\title{
The Determinants of e-Trade Utilization and Its Impact on Exporter Performance in Korean SMEs
}

\author{
Byoung-Goo KIM \\ Associate Professor, Division of Global Business, Hanshin University, Korea \\ E-mail: bgkim@hs.ac.kr
}

Received: February 15, 2020. Revised: February 26, 2020. Accepted: March 2, 2020.

\begin{abstract}
Purpose - This paper tries to analyze the factors affecting the utilization of electronic trade of small and medium enterprises and examine how these factors affect the performance of small and medium enterprises. In addition, the leading factors affecting the level of e-trade utilization of small businesses were analyzed by dividing them into external environmental factors affecting the external business and internal resources of the companies themselves

Research design, data, and methodology - With a sample of 223 small and medium-sized export firms from South Korea, this study investigates the antecedents of the utilization level of e-Trade such as information exchange, innovation orientation, absorptive capacity and trust by hierarchical regression analysis.

Results - The results show that innovation orientation was shown to have a positive effect on e-trade utilization and absorptive capacity has a positive effect on e-trade utilization. Also, information exchange with stakeholders has a positive impact on e-trade utilization.

Conclusions - Internal and external factors of companies have a positive effect on the utilization of e-trade. It also showed that the increased utilization of electronic trade had a positive effect on trade performance. Thus, the findings provide policy-makers with implications of the importance of activating e-trade, and furthermore, significant implications for exporter performance.
\end{abstract}

Keywords: E-trade, Export, Trust, Information exchange, Innovation orientation, Absorptive capacity.

JEL Classification Code: F20, F23, L10. 


\section{Introduction}

With the recent drastic change in the information and communication environment and the improvement of the Internet network environment, the e-trade infrastructure is increasingly developing. In the meantime, the government has been trying to enhance its trade competitiveness through a support system that serves as a single channel for electronic trade, such as uTradeHub. Individual companies may also be able to more easily access foreign buyers through external export consulting firms and get a lot of help in selling products.

In terms of the nature of business related to trade, we can summarize three things: trade information, brokerage and document processing (Lee, 2012). In other words, directly and indirectly, the middleman of the transaction such as general trading company, trader. Distributor will be involved in negotiating the terms of the transaction with a potential client based on trade information. And in the process of carrying out the contract, the trade will be handled around documents in accordance with the regular procedures and regulations.

The common perception of the relevance of e-trade has largely resulted in two aspects. One is the creation of a new market using virtual space and the aspect of economic maximization through time reduction and cost reduction. South Korea and many other major countries are seeking to expand electronic trade by strengthening the international cooperation system between countries or regions in order to establish their own e-trade environment and carry out global e-trade.

Electronic trade not only reduces various costs and increases the efficiency of trade by electronicizing trade procedures, but also plays a very important role in carrying out marketing strategies such as exploring overseas markets. In fact, major advanced countries such as the United States, Britain and Japan have already adopted e-trade as an important national task, continuing to improve their trade IT infrastructure (Han \& Choi, 2013).

Korea, which had pursued its economic development strategy through trade, has also been very active in implementing Electronic Data Interchange (EDI) into the trade sector in order to improve trade systems and procedures and enhance the efficiency of trade operations through IT. Despite such diverse efforts by the government and related government agencies, however, the e-trade utilization rate of small and medium-sized companies is not as high as expected. It is understood that the use of e-trade by SMEs is mainly made in e-trade marketing, which requires an essential shift in that small businesses do not enjoy the practical benefits of e-trade.

Therefore, in order to spread the use of e-trade technology or innovation, it is necessary, among other things, to demonstrate what positive effects a firm can achieve from these technologies or innovations. In this respect, a number of prior studies have been carried out to prove the effectiveness of e-trade (Kim, 2004; Yoon \& Kim, 2011; Lee \& Kim, 2012; Lee, Kang, \& Cho 2011). In addition, a large part of the research that reviewed the effectiveness of electronic trade through empirical research shows that the higher the utilization level of electronic trade, the higher the corporate performance through electronic trade.

In addition, there are prior studies on factors affecting the utilization of e-trade, but not many papers dealing with empirical analysis of e-trade at the small and medium-sized business level have shown consistent results(Jeong \& Lee, 2015; Choi, 2005; Han \& Choi, 2013). Therefore, this paper tries to analyze the factors affecting the utilization of electronic trade of small and medium enterprises and examine how these factors affect the performance of small and medium enterprises. In addition, the leading factors affecting the level of e-trade utilization of small businesses were analyzed by dividing them into external environmental factors affecting the external business and internal resources of the companies themselves.

The differentiation from previous studies was analyzed by assuming reliability and information exchange with stakeholders, innovation orientation at the organizational level, and the organizational absorptive capacity as independent variables, which were not adequately addressed in the preceding study. In addition, the relationship between e-trade utilization and corporate performance was analyzed.

\section{Theoretical Background and Hypothesis Setting}

\subsection{Definition and Characteristics of Electronic Trade}

Electronic trade refers to a new form of trade transaction by electronicizing all trade transactions, such as collecting market information at home and abroad, finding overseas buyers, and searching information and contracting import and export through the Internet, a computer network. Whereas traditional trading methods are paper transactions, e-trade based on information and communication technology is to carry out paperless trade through the use of the Internet and electronic data inter-change (EDI). Through this, changes in the existing trading 
style and practices are seen as a commercial revolution in that companies make the most of the benefits of ecommerce as well as reducing costs, securing competitiveness.

The concept of e-trade includes not only the procedures of trade transactions but also the subject of trade transactions of tangible goods itself, and the concept of electronic trade can be applied even if the object of trade is electronic intangible goods such as digital content. Electronic trade is the widest trade in terms of carrying out trade transactions using various information media in electronic ways such as the Internet, including the concept of ecommerce. The Foreign Trade Act stipulates that e-trade refers to transactions made using information communication networks and devices that have computer or some parts of the trade (Article 1 Section 6 of the Foreign Trade Act).

If we compare the characteristics of e-trade with existing trade transactions, the characteristics are as follows. First, e-trade targets markets all over the world. Because the Internet transcends the limits of space, markets that have been divided by countries are integrated into one market. Thus, at minimal cost, advertising can be conducted around the world without restriction of time and space, and trade deals can be made with anyone anywhere in the world at any time.

Second, e-trade makes it easy to get all the information about the market. Under the existing trade deals, it took a lot of time and money to find a client and used a trade broker due to a lack of information. In electronic trade, however, it will be easy to find out which companies in certain countries are supplying certain goods through the Internet. In addition, because market information can be obtained in real time, a thorough market principle is applied to the parties that need a particular product so that transactions are made on the most reasonable basis.

Third, e-trade reduces trade transaction costs. In traditional trade deals, it took a lot of money and time to obtain information, consult or exchange documents to close a deal. In e-trade, however, communication costs are reduced because information and documents are exchanged over the Internet. In addition, a payment system related to etrade is developed to ensure safe and secure payment, which can reduce financial fees.

Fourth, the price of a product or service will be reduced at the source when e-trade is conducted. The distribution structure of e-trade is simple because exporters and importers are directly linked via the Internet, which reduces distribution costs by that much. And with the disclosure of information about the production process, the price structure will be leveled, causing prices of products or services to fall across the board.

Fifth, the scope of activities of small and medium-sized enterprises will be expanded in e-trade. Using the Internet, small and medium-sized enterprises can also build networks to advertise or market-researching around the world, which was previously monopolized only by large companies.

\subsection{Literature Review}

Trade work has a value chain with a variety and complexity. In the case of a transaction selection conducted as part of an overseas market survey in implementing a complex trade operation, the company used to import and export goods through traders or general trading companies and to sell or distribute goods through distributors such as wholesalers and retailers. Recently, however, dependence on traditional function brokers has been reduced as various e-market places have been established by trade portal sites and trade transaction sites and by industry, item and region. Instead, information intermediaries or marketers which is to create new business opportunities based on information about sellers and buyers, or provide customized services or transaction placement are increasingly playing an important role.

Due to the revitalization of electronic trade in Korea, related research has been carried out steadily since the early 2000s. Until now, the research topics have largely consisted of e-trade marketing topics, electronic trade settlements, electronic trade information systems and general electronic trade. In the early 2000 s, research mainly presented the spread to research on the overall subject of e-trade, such as business automation using EDI, Internet ecommerce, and related legal issues, proposed the continued expansion of systematic and professional research, and specifically researched on research subjects and analysis methods.

There are previous studies that analyze the relationship between e-trade utilization and performance have been conducted steadily from 2007 to 2015. These studies are largely divided into topics that analyze only the factors of e-trade use through empirical analysis or study the relationship between factors and performance, and literature that deals with the limitations and activations of e-trade utilization. As a prior study, Choi and Choi (2008) analyzed the e-trade environment, degree of utilization and economic performance in Northeast Asia. It analyzed differences through e-trade environment, utilization, and performance factors of five Northeast Asian countries and analyzed the impact of the e-trade environment and utilization on performance of five Northeast Asian countries.

Jung and Lee (2015) tried to find out how it affects the utilization level and utilization performance of e-trade among Chinese companies in eastern China's coastal areas, and also identify the factors that affect the use of e-trade. 
The study found that the degree of support from government-related agencies and the intensity of competition in the industry as external factors for businesses affected the utilization of electronic trade. Corporate internal characteristic factors showed that the innovation and organizational suitability of CEOs had a positive impact on etrade utilization levels.

Han and Choi (2013) analyzed the factors affecting the use of electronic trade by SMEs and looked at how these factors affect the performance of SMEs. In addition, the antecedent factors affecting the level of small businesses' etrade execution were analyzed by dividing them into external environmental factors that would affect the level of businesses' internal resources. In addition, an integrated model on the implementation and performance of e-trade was constructed by combining a technology acceptance model (TAM) that could explain the proliferation of e-trade from the perspective of the acceptor.

Dong and Choi (2014) examined external environmental factors, internal environmental factors, and cognitive factors extracted from technology acceptance models for small and medium enterprises as factors affecting the adoption of electronic trade among small and medium-sized enterprises. It analyzed how these influencing factors increased the level of e-trade utilization of companies and thus their corporate performance. According to the analysis, the infrastructure of the information system has a greater impact on the utilization level of e-trade than on the support of the CEO and the IT capabilities of the staff. In this respect, the most important resource for improving the utilization level of electronic trade is the information system infrastructure. It was also found that perceived ease of use and perceived usefulness both had a significant effect on the utilization range of e-trade.

Foreign previous studies have shown that environmental characteristics, consisting of competitive pressures in the industry, perceived benefits, organizational readiness, influence of external pressures, participation of trading partners, information intensity and competitive strength in the industry, enhance the level of e-trade activation (Iacovou et al., 1995; Chwelos et al., 2001). Machuca and Barajas (2004) report that companies that utilize EDI reduce the cost of average inventory and significantly improve the performance of supply chain management. Other studies also said that the level of utilization of electronic trade is affected by the relationship of power with the trading company, which is more affected by persuasive recommendations rather than by the use of force, and that external pressure has the greatest impact on the introduction of the information system (Hart \& Saunders, 1997; Charamboset et al., 1995).

A number of previous studies that describe internal resources factors affecting the utilization of electronic trade include the firm size, the functional differentiation of the organization, technical compatibility, innovation or support of the CEO, education or training on electronic trade, and infrastructure as key factors.(Carter et al., 1987; McGowon, 1994: Anderson \& Larsen, 2008).

Looking at the extant studies on the acceptance and diffusion of electronic trade, several studies suggest that the level of internal and external integration with the environment of the organization is affecting the use of EDI, and that the higher the degree of industrial-side variables, the greater the introduction and utilization of information systems between companies, and the influence of customers and the degree of connectivity between internal trading parties, affects the environment.(Bergeron \& Raymond, 1992; Grover, 1993). Crook \& Kumar (1998) argued that environmental factors affect the implementation of EDI and that the impact may change depending on the contextual conditions such as the perception of increased customer service, the perception of cost savings within the enterprise, and the pressure from competitors. McGowon (1994) studied how widespread the use of EDI in the organization can be, using variables of scope, depth of execution, and sophistication.

\subsection{Internal Factors and Utilization of Electronic Trade}

\subsubsection{Organization's Innovation Orientation}

Innovation can be defined as reflecting creative new things in business, management, production. Damanpo (1991) defines innovation as an organization adopting new equipment, systems, policies, programs, processes, products and services. Thus, under this definition, innovation can be identified as a broad concept that can be applied to all sectors of the organization and to all aspects of the organization. The study does not focus on the act of innovation itself, but rather on the direction of the organization's thinking, which is the direction of the organization's innovation orientation, which causes such innovation to occur over the long term. Orientation refers to the organization's continuous and holistic mindset, which allows and manipulates the direction of action to be taken by the organization (Harmsen et al., 2000). Thus, innovation orientation is defined as the continuous and holistic thinking direction of an enterprise that seeks to secure a competitive advantage by creating or introducing new technical knowledge or ideas related to new products, services and processes. 
Innovation orientation is identified as an adaptive mechanism that coordinates interactions with the environment of an entity and can be considered as the concept of an entity's organizational culture or management philosophy (Hakala, 2011; Talk et al., 2011; Zhou et al., 2005). The importance of innovation orientation as a concept of this strategic orientation can be understood as a higher concept than that of innovation in that it serves as a mental guide for an enterprise that ultimately creates an entity's ability to innovate and thus a competitive advantage.

The innovation orientation of an organization can be identified to the extent that it wants to "introduce relatively new things earlier than its competitors," compared to other competitors, to a more active level of innovation (Bunkken \& Sascha, 2013; Hultman, Robinson, \&, Katsikeas, 2009). Innovation orientation is also the willingness to find new things before others (Eöke-Szidónia, 2015), where companies tend to derive and implement creative ideas from their management activities (Perlines \& Lozano, 2017). Innovation orientation is the ability to embrace new ideas and create and implement new processes, new products or new services in foreign businesses (Kuvalainen, Sundqvist, \& Servais, 2007). In other words, innovation orientation is the organizational ability to execute creative ideas.(Kuivalainen, Sundqvist, \& Servais, 2007). The Heba (2013) defined innovation orientation as the corporate and cultural dimension as an organizational atmosphere that encourages new ideas. Innovation orientation was also viewed as creative ideas, new processes, physical work pieces, an active attitude toward problem solving, an attitude to determine organizational activities, and an organizational willingness to take bold action to achieve goals.

Prior studies on the impact of innovation on exports simply revealed that technology transfer agreements or technology licenses from outside the company cannot produce significant results in exports, and that companies should be innovative in their own right to creatively engage in innovative activities on their own (Ozselik \& Taymaz, 2004).

Innovation orientation refers to the tendency to support creativity, novelty and research and development in the development of products, services and processes (Lisboa, Skarmeas, \& Saridakis, 2016).

In overseas markets, companies need greater innovation than their competitors. In other words, companies that implement high levels of innovation-oriented behavior will be able to gradually deliver innovative products and services to foreign markets through continuous market creation and exploration.

Export experts also said that export workers should repeatedly promote and apply innovative activities in order to maintain innovative management activities (Hughes et al., 2007). The more innovative companies are, the more likely they will be to utilize new e-trade. Therefore, the following hypothesis was established with the above logic.

H 1: The higher the organizational innovation orientation, the more positive the utilization of e-trade.

\subsubsection{Organizational Absorptive Capacity}

Cohen and Leventhal (1990) conceptualized the learning capacity required for an entity to adapt to its environment as an absorptive capacity, which they called the ability of the entity to explore, recognize, and acquire outside new knowledge or information to commercialize it. They argue that if organizations have knowledge about it in advance when they acquire new knowledge or information, it is much more efficient to accept and also very easy to get new products or ideas. Cohen and Leventhal (1990) introduced the absorptive capacity of an enterprise to innovate, which is dynamic tendency. Subsequently, the concept of absorptive capacity was expanded to interorganizational, intra-organizational, and country level, and Zahra and George (2002) expanded the concept of absorptive capacity to the concept of dynamic capacity through a review of literature. In other words, the absorptive capacity was redefined as a task performance process in which the entity acquires new knowledge, assimilates, transforms and exploits it.

Management strategy researchers have argued that a company's strategy is a product of its external environment and internal capabilities. In the case of export strategy, the external environment means the export market environment, and the internal capacity means organizational resources and capabilities. The assets and capabilities of the enterprises required for export include the superiority of scale (Reid,1982), the degree of international experience (Douglas and Craig, 1989), the degree of intervention in international management activities, and resources to need export activity (Cavusgil \& Zou, 1994). Once an export firm has these resources and capabilities, it will be able to identify the characteristics of the e-trade system through technological development and innovation and develop appropriate export strategies to implement them effectively. Therefore, it can be seen that the organizational characteristics, such as resources, capabilities and international experience, directly affect its export strategy.

In addition, the higher the organization's absorptive capacity, the more actively it introduces and applies new technology changes and technologies, thereby having a positive impact on the organization's ability to enhance its 
capabilities. In this study, the hypothesis is established as follows based on the views of scholars who stressed the importance of the ability of an enterprise to recognize and explore the value of new knowledge and the views of scholars who argued that the ability to integrate and utilize new knowledge should be developed.

H 2: The higher the absorptive capacity of export firm, the more positive the utilization of e-trade.

\subsection{External Factors and Utilization of Electronic Trade}

\subsubsection{Characteristics of relationships with stakeholders}

Online trust from a stakeholder's point of view has recently generated a lot of interest. Different stakeholders have different perspectives and requirements for online trust. From a customer's perspective, an entity's website needs trust value to do business and to obtain reliable customer information and services. On the other hand, from the supplier's perspective, the main requirements may be validity, easy access to purchaser information, and preservation of confidential information. And from the shipper's point of view, online trust needs may be the diversity of channels. These diverse perspectives may depend on offline relationships with stakeholders. For example, the stakeholders' perception of online trust in a single entity may depend on a balance of power between the entity and its channel members (Lee, 2006).

In stakeholder theory, the main issue is economic validity. The economic effectiveness in this context is related to an entity's ability to manage the interests of various stakeholders. Because the interests of some stakeholders vary in the context of online trust, the views of different stakeholders make it difficult to align the economic validity of a firm easily. Building and maintaining a website with a high level of trust with different stakeholders may require an elaborate balance of the interests of these stakeholders.(Freeman, 1994).

As such, trust in electronic trade is one of the very important factors in transactions and one of the concepts that has been dealt with in marketing when defining the characteristics of the relationship between consumers and sellers. Most entities want to maintain ongoing transactions with vendors and traders, such as manufacturers, and maximize the efficiency of the entity to affect the performance of the entity. As such, the following hypothesis was set, expecting that trust with stakeholders would affect the utilization of e-trade.

H 3: The higher the trust with stakeholders, the greater the utilization of e-trade.

Choi (2003) explained that if companies experience that they cannot obtain the desired offer information no matter how much transaction information is provided, they will have a negative impact on the electronic trade environment. Shim (2013) analyzed the relationship between e-trade reliability and utilization level and found that the items of usefulness have a positive effect on the level of qualitative use (foreign promotion marketing, finding trading lines, gathering information on overseas markets, and making electronic catalogs). It also explained that it is an important factor in determining the degree of use of electronic trade in terms of contract settlement and implementation stages. Summing up the above results, it can be expected that accurate sharing of information with customers and internal employees will have a positive effect on the e-trade of exporters in order to enhance the level of use of electronic trade by companies.

Hart and Saunders (1997) stated that the level of use of EDI is affected by the relationship of power to the trading partners, which is more affected by persuasive recommendations than by the use of force. Charalambos et al. (1995) argued that external pressure has the greatest effect on the introduction of the information system, and that external pressure is made through suppliers, government agencies and customers. According to Yoon et al. (2008), external factors, consisting of the influence of trading partners and the strength of competition within industries, have a major impact on e-trade utilization levels and corporate performance. Summing up the above results, this study can expect that a active exchange of information with stakeholders will have a positive impact on the level of e-trade utilization of companies.

H 4: The more information exchanges with stakeholders, the greater the utilization of e-trade. 


\subsection{Utilization of Electronic Trade and exporter Performance}

Recent research trends in electronic trade have been steadily researched as a study on the utilization and performance of electronic trade, and a study on policies to promote electronic trade by Korean exporters. this part examines previous studies that use of electronic trade has a direct impact on the performance of electronic trade. Lee, Kang and Cho (2011) said that the use of electronic trade by small and medium-sized Chinese companies has a positive impact on their performance. This study focuses on empirical analysis of what factors influence the use of electronic trade by small and medium enterprises in China and the economic performance of electronic trade. To this end, this study was to establish research models and hypotheses by dividing factors that could affect the utilization level and performance of electronic trade into external factors, internal factors and relationship characteristics, and to verify the significance of the hypotheses on the extent to which each factor affects e-trade utilization and performance. This has shown that e-trade utilization levels have a significant impact on e-trade utilization performance. Based on this, it presented implications and policy directions for revitalizing the electronic trade of small and medium enterprises in the future.

In Kwon and Oh (2007)'s analysis of e-trade exports and factors, corporate performance was divided into financial and non-financial performance. Financial performance was divided into reduced operating costs, transaction costs, and navigation costs, while non-financial performance was analyzed by dividing it into reduced working hours, improved customer service, enhanced competitiveness, and improved corporate image. In addition, utilization and measurement factors were identified as short-term and long-term gains in the study of Emelhainz (1990),

Short-term profits were divided into tracking sales and commodity flows, faster payment cycles, shorter order processing times, reduced data entry errors, improved fund management, reduced filing costs and shared information among trading companies. The long-term profits was divided into enhancing corporate competitiveness, improving business efficiency, and developing new business opportunities through maturity of the organization's IT conditions.

In Kwon (2009) study, the e-trade utilization and measurement factors were divided into short-term and longterm performance. Short-term performance was divided into cost reduction, business processing time reduction, payment period reduction, and cost reduction, and long-term performance divided into standardization of transaction procedure, convenience of organization management, quality improvement of members, securing competitive advantage, and ease of entry into the market. In this paper, the enterprise performance of e-trade was divided into economic and non-economic achievements. Here, economic performance refers to reduced transaction costs, decreased marketing costs, increased trade volume, and increased number of trade transactions, while non-economic performance means improved transaction relations, improved corporate image, potential customer creation, improved work efficiency, differentiated from competing companies, and improved overseas markets.

Kim and KIm (2007) suggested that the higher the utilization performance of e-trade, the more tangible results companies can achieve, such as productivity improvement and profit creation, improved mutual benefits with trading companies, and stronger relations. It also suggested that in terms of economic feasibility, the government can achieve improvements in the national image, such as reduction of trade expenses and improvement of export competitiveness.

Lee (2004) studied the factors affecting the overall use and efficiency of electronic trade, such as collecting information on overseas markets, finding trading lines, overseas promotion of export products, marketing, transaction negotiation, trade work, and information security, regardless of the size of companies. An empirical analysis of the E-trade acceptance and satisfaction of traders shows that the speed of trade work and potential customers for overseas trading lines has increased, and diversified by utilizing e-trade. In addition, this study shows that the actual trade is going well and that the overall satisfaction level has increased. It was also analyzed that because of the significance of utilizing e-trade, e-trade will be continuously utilized and that it would like to recommend other trading companies to utilize e-trade.

As such, a combination of prior studies on e-trade utilization and corporate performance shows that the difference in corporate performance is reflected by the utilization of e-trade. Therefore, the following hypothesis is established.

H 5: The higher the use of e-trade, the more positive it will have on corporate performance. 


\section{Research Methodology}

\subsection{Data Collection and Analysis Methods}

The data from this study was collected via e-mail and fax from the address book of local trading companies and from the Korea International Trade Association in 2017 to randomly selected companies. This study partially modified the questionnaire after conducting a pilot study to select and refine the survey items, and the survey period was from February to July 2017, during which a total of 400 copies were distributed and 230 copies were collected. 223 questionnaires were used for the analysis, except for those that were not useful for the content analysis or were not responding.

\subsection{Measurement of Variables}

The independent and dependent variables used in this study are a total of six variables. First, innovation orientation was measured by four questions, and absorptive capacity was measured by four questions. In relationships with stakeholder, the trust variables were measured in three questions and the information exchange variables were measured in four questions. The utilization level of electronic trade for use as a dependent variable was measured in two questions, and the performance variables were measured in five items. The control variables considered firm age and size.

First, innovation orientation was measured in four questions such as i) new technology orientation in product / service development, ii) respond quickly to competitor's technology changes, iii) systematically explore new technology trends of our industry, iv) active support for personnel, funds, and equipment required for the introduction of new technologies according to previous studies of Avlonitis et al.(1993), Talke et al.(2011), Siguaw et al.(2006).

Second, absorptive capacity was measured in four questions including i) high ability to learn knowledge and experience about management and organizational skills, ii) high ability to develop or reinvent new resources and capabilities, iii) ability to partner, collaborate with external companies and agencies, iv) utilize other corporate successful practices to absorb knowledge or technology according to the research such as Cohen and Levinthal (1990), Rosenkopf and Nerkar (2001), Kogut and Zander (1992).

Third, trust was measured in three questions such as i) Degree of honest dealings with a client, ii) degree of trust in an appointment with a client, iii) degree of follow-up management when a problem occurs according to the studies of Jarvenpaa and Todd (1997), Yoon (2000).

Fourth, information exchange was measured in four questions including i) the degree of providing proprietary information for internal infrastructure, ii) the degree to which continuous (real-time) information is provided, iii) the degree to which information is delivered quickly and actively, iv) the degree to which important events or changes are provided in the management activities (Noh \& Chung, 2003).

Fifth, utilization of e-trade was measured in two questions such as i) daily average usage time of E-trade system, ii) the number of contracts according to the studies of Kim and Joo (2010).

Last, exporter performance was measured in five questions including i) satisfaction with expectations on export performance over the past three years, ii) increase of potential buyers, iii) degree of reduction in transaction costs, iv) degree of reduction in logistics costs, v) degree of reduction in contract settlement costs by Son (2011)

\section{Empirical Analysis}

\subsection{Reliability and Validity Verification}

The Crobach's apha value was calculated to verify the internal consistency of each variable's measurement items. Reliability analysis results are described in $<$ Table $1>$ below. The Crobach's apha value of all variables shows a typical reliability acceptance level of 0.6 or higher, which is judged to be free of internal consistency problems.

Factor analysis was performed to test the validity of each variable. The factor analysis method extracted factors based on eigen value 1 using a varimax rotation method of the principal component analysis. Factorial analysis results (see Table 2) showed that each variable was properly loaded, and each item described about $74.8 \%$ of the total variance, showing relatively high variance explanatory power. In addition, factor loading values for each factor 
also appear to be above the general acceptance level of 0.5 and are judged to be free from problems with discriminant validity and convergent validity.

To solve the problem of common method bias, all variables were measured in multiple or multiple items (Podsakoff \& Organ, 1986), and the measurement questions of dependent variables were placed behind the independent variable-related questions, reducing the likelihood of respondents predicting and responding (Salancik \& Pfeffer, 1977).

Table 1: Varimax-Rotated Factor Analysis

\begin{tabular}{|c|c|c|c|c|c|c|c|}
\hline Items & 1 & 2 & 3 & 4 & 5 & 6 & Cronbach's alpha \\
\hline Performance 5 & .904 & -.033 & .057 & . 109. & .003 & .041 & \\
\hline Performance 2 & .869 & .017 & .061 & -.086 & .067 & .168 & \\
\hline Performance 1 & .841 & .055 & .112 & .047 & .219 & .069 & 0.906 \\
\hline Performance 3 & .828 & .125 & .128 & -.224 & .099 & .097 & \\
\hline Performance 4 & .746 & .138 & .207 & .003 & -.216 & .021 & \\
\hline Information 2 & .076 & .954 & .045 & .096 & .061 & .064 & \\
\hline Information 4 & .035 & .907 & .004 & .092 & .155 & .091 & 0.904 \\
\hline Information 3 & .048 & .859 & .142 & -.001 & -.059 & .067 & \\
\hline Information 1 & .116 & .705 & -.062 & .283 & .289 & .085 & \\
\hline ACAP 4 & .077 & -.009 & .861 & .133 & .090 & .027 & \\
\hline ACAP 2 & .093 & .087 & .836 & .171 & .066 & -.032 & 0.865 \\
\hline ACAP 3 & .147 & .009 & .828 & -.006 & .113 & .096 & \\
\hline ACAP 1 & .180 & .066 & .741 & .068 & -.067 & .252 & \\
\hline Innovation 4 & -.029 & .057 & .226 & .873 & .053 & .028 & \\
\hline Innovation 1 & -.056 & .123 & .008 & .801 & .075 & .075 & \\
\hline Innovation 3 & -.030 & -.046 & .293 & .794 & .006 & .137 & 0.851 \\
\hline Innovation 2 & .003 & .274 & -.099 & .755 & -.001 & .196 & \\
\hline Trust 2 & .116 & .109 & .174 & .118 & .808 & -.248 & \\
\hline Trust 1 & -.023 & .061 & -.065 & .018 & .800 & .141 & 0.727 \\
\hline Trust 3 & .059 & .121 & .117 & .001 & .735 & .126 & \\
\hline Utilization 2 & .133 & .058 & .222 & .188 & .024 & .799 & 0.752 \\
\hline Utilization 1 & .215 & .240 & .071 & .216 & .096 & .746 & \\
\hline Eigen Value & 5.464 & 3.471 & 2.755 & 1.936 & 1.761 & 1.072 & \\
\hline Variance $(\%)$ & 24.836 & 15.779 & 12.522 & 8.801 & 8.002 & 4.874 & \\
\hline Cumulative V (\%) & 24.836 & 40.615 & 53.137 & 61.938 & 69.941 & 74.815 & \\
\hline
\end{tabular}

In addition, verification using Harman (1967)'s single factor test resulted in six components in the principal component analysis, with the most descriptive component accounting for $74.8 \%$ of the total variation. Therefore, it is judged that there is no problem with common method bias as the distributed explanatory power of a particular factor that is not absolute. 


\subsection{Correlation Analysis}

To test the hypothesis, correlations between each variable were performed before multiple regression analyses were performed. Correlation analysis results are shown in $<$ Table $2>$ below. As shown in the results below, although the relatively high correlation between each variable is suspected, the VIF analysis shows that there is no problem.

Table 2: Pearson Correlation

\begin{tabular}{|c|c|c|c|c|c|c|c|c|c|c|}
\hline Variable & Mean & St. dev & 1 & 2 & 3 & 4 & 5 & 6 & 7 & 8 \\
\hline 1. Innovation Orientation & 3.825 & 0.718 & 1 & & & & & & & \\
\hline 2. Absorptive Capacity & 3.902 & 0.763 & $0.255^{* * *}$ & 1 & & & & & & \\
\hline 3. Trust & 3.353 & 0.656 & $0.123^{*}$ & $0.151^{* *}$ & 1 & & & & & \\
\hline 4. Information Exchange & 2.776 & 0.811 & $0.256^{* * *}$ & $0.119^{*}$ & $0.248^{* * *}$ & 1 & & & & \\
\hline 5. Level of Utilization & 3.870 & 0.911 & $0.373^{* * *}$ & $0.309^{* * *}$ & $0.139^{* *}$ & $0.313^{* * *}$ & 1 & & & \\
\hline 6. Performance & 3.167 & 0.629 & -.026 & $0.279^{* * *}$ & $0.120^{*}$ & $0.151^{* *}$ & $0.310^{* * *}$ & 1 & & \\
\hline 7. Size & 3.420 & 0.431 & .039 & .056 & -.007 & -.030 & $0.113^{*}$ & .067 & 1 & \\
\hline 8. Age & 2.507 & 0.485 & -.034 & .072 & $0.125^{*}$ & .068 & .059 & .013 & .029 & 1 \\
\hline
\end{tabular}

\subsection{Verification of Research Hypotheses}

\subsubsection{Basic Analysis Results}

It analyzed how the organizational internal factors including innovation orientation and absorptive capacity and its relationship with external stakeholders including trust and information exchange were affecting the level of utilization of e-trade. This hierarchical regression consists of Model 1, Model 2, and Model 3. Here, Model 1 is proposed to examine how much influence the control variable has on the dependent variable, and Model 2 is intended to look at the influence between the internal factors of the entity and the level of e-trade utilization when it has controlled this part. Finally, Model 3 is a full model of how all independent variables influence e-trade utilization levels.

In $<$ Table $3>$, the full model of this study had 22.4\% Adj R2, indicating a relatively high explanatory power of the model. In addition, it is judged that there is no problem with the conformity of the model because the $\mathrm{F}$ value is significant at the 1\% level. The value of the Variance Inflation Factors (VIFs) shows a value of 1.007 to 1.134 , which makes it unlikely that the regression's multicollinearity will occur.

\subsubsection{Hypothesis Verification on the utilization level of E-trade}

First of all, there is the influence of the firm size and age as control variables on the utilization of electronic trade in Model 1. The verification results show that the larger the company, the higher the level of e-trade utilization $(t=1.646$, p0.0.1). However, it was found that the age of the entity had no significant effect.

As the organizational internal factors, Hypothesis 1 expected that the stronger the innovation orientation of the organization, the higher the level of utilization of e-trade. Regression results show that hypothesis 1 is supported $(\mathrm{t}=4.111 ; \mathrm{p}<0.01)$. Hypothesis 2 expected that the higher the absorption capacity of an organization, the higher the utilization level of electronic trade. As a result of the analysis, hypothesis 2 was supported $(\mathrm{t}=3.327, \mathrm{p}<0.01)$. In other words, the higher the innovation orientation and absorption capacity of the organization among the internal environmental factors of the organization, the higher the level of utilization of e-trade is, the more important internal resources are identified.

Next, looking at two hypotheses related to external stakeholders. Hypothesis 3 expected that the higher the level of trust with stakeholders, the higher the utilization of e-trade. The result showed that hypothesis 3 was rejected. Hypothesis 4 expected that the more information is exchanged with stakeholders, the higher the utilization of e-trade. As a result of the analysis, hypothesis 4 was supported $(\mathrm{t}=3.472, \mathrm{p}<0.01)$. 
$<$ Table $4>$ is a regression analysis of how e-trade utilization affects corporate performance. As a result of a regression analysis on the relationship between e-trade utilization and enterprise performance, hypothesis 5 was supported $(\mathrm{t}=4.741, \mathrm{p}<0.01)$. Details of the results of hypothesis 1 to 5 are discussed in the discussion and conclusion sections.

Table 3: Regression Analysis

(Dependent Variable: Utilization of E-trade)

\begin{tabular}{|c|c|c|c|c|c|c|c|}
\hline \multirow[b]{2}{*}{ Variables } & \multirow[b]{2}{*}{ VIF } & \multicolumn{2}{|c|}{ Model 1} & \multicolumn{2}{|c|}{ Model 2} & \multicolumn{2}{|c|}{ Model 3} \\
\hline & & $\mathrm{b}$ & t-value & $\mathrm{b}$ & t-value & $\mathrm{b}$ & $\mathrm{t}$-value \\
\hline \multicolumn{8}{|l|}{ Control Variables } \\
\hline Size & 1.007 & .112 & $1.676^{*}$ & .088 & 1.441 & .098 & $1.646^{*}$ \\
\hline Age & 1.027 & .056 & .835 & .052 & .846 & .033 & .553 \\
\hline \multicolumn{8}{|l|}{ Internal Variables } \\
\hline Innovation Orientation & 1.142 & & & .315 & $5.020^{* * *}$ & .260 & $4.111^{* * *}$ \\
\hline Absorptive Capacity & 1.095 & & & .220 & $3.492^{* * *}$ & .206 & $3.327^{* * *}$ \\
\hline \multicolumn{8}{|l|}{ External Variables } \\
\hline Trust & 1.097 & & & & & .019 & .300 \\
\hline Information Exchange & 1.134 & & & & & .219 & $3.472^{* * *}$ \\
\hline Adj. R & & & 0.07 & & 0.184 & & .224 \\
\hline F-stat. & & & 1.795 & & $13.515^{* * *}$ & & $11.670^{* * *}$ \\
\hline $\mathrm{N}$ & & & 223 & & 223 & & 223 \\
\hline
\end{tabular}

Table 4: Regression Analysis (Dependent Variable: Exporter Performance)

\begin{tabular}{llllll}
\hline & & & Model 1 & & \multicolumn{2}{c}{ Model 2} \\
Variables & VIF & b & t-value & b & t-value \\
\hline
\end{tabular}

\section{Control Variable}

\begin{tabular}{|c|c|c|c|c|c|}
\hline Size & 1.014 & .067 & .998 & .033 & .506 \\
\hline Age & 1.004 & .012 & .172 & -.006 & -.087 \\
\hline \multicolumn{6}{|l|}{ Independent Variable } \\
\hline Utilization of E-trade & 1.016 & & & .307 & $4.741^{* * *}$ \\
\hline Adj. R & & & 0.004 & & 0.085 \\
\hline F-stat. & & & 0.518 & & $7.871^{* * *}$ \\
\hline $\mathrm{N}$ & & & 223 & & 223 \\
\hline
\end{tabular}




\section{Discussion and Conclusion}

This paper comprehensively examined external and internal factors in terms of relations with external stakeholders as factors affecting the utilization level of electronic trade among small and medium enterprises in Korea. An analysis was conducted on the extent to which these antecedent factors would increase the level of e-trade utilization of a company and thus affect its corporate performance. In this study, hierarchical regression was used to control the age and size of companies that could affect the level of e-trade utilization so that they could be analyzed more closely. Based on the results of the empirical analysis, the contents of this study are discussed and summarized as follows.

First, it has been shown that the internal factors of companies are having a positive effect on the level of e-trade utilization. More specifically, the stronger the innovation orientation of the organization, the higher the level of utilization of e-trade. These results can be seen as supporting a prior study in which an organization with a high degree of innovation orientation compared to other competitors, introducing a relatively new one earlier than its competitors and seeking to implement the innovation more actively (Bouncken \& Sascha, 2013; Hultman, Robson, \&, Katsyas, 2009). In addition, the higher the absorptive capacity of an organization, the higher the level of utilization of e-trade, due to internal factors of a company. These results are in support of leading studies that demonstrate that companies with high absorption capacities can obtain new knowledge, assimilate, transform and leverage (Zahra \& George, 2002).

Second, when looking at the factors related to external stakeholders as external factors of the entity, the higher the level of trust with the stakeholders, the higher the utilization of e-trade was expected. However, the analysis did not produce significant results. These results can make it difficult for different stakeholders to align the economic validity of a firm easily, because the interests of stakeholders vary in the context of online trust. Therefore, it is believed that the website with a high level of trust with different stakeholders could not have produced significant results (Freeman, 1994) because it is difficult and time-consuming to build and maintain.

The result of hypothesis 4 shows that the higher the level of information exchanges with stakeholders, the higher the e-trade utilization. It seems that if reliable information and services can be exchanged between stakeholders actively, this naturally results in companies becoming interested in the e-trade system and higher levels of utilization. These results are in line with the study that the reliability of transaction information and websites will be increased by the experience of obtaining the desired offer information among the company's mutual information (Choi, 2003), which will have a positive impact on the e-trade environment.

Third, an analysis was conducted on how the higher the level of e-trade utilization in these organizations would affect the performance of companies. The analysis results showed that the level of e-trade utilization has a positive effect on corporate performance. These results are in agreement with the propriety of e-trade. In other words, e-trade is the creation of a new market using virtual space and aspects of maximization of economy by reducing time and cost. It is an empirical analysis of the argument that e-trade procedures not only reduces various costs and increases the efficiency of trade, but also plays a very important role in carrying out marketing strategies such as exploring overseas markets.

In addition to these academic contributions and implications, the results of this study also provide managerial implication. First, not only large firms but also smaller companies need to faithfully provide support and investment for internal and external resources. In other words, increasing organizational innovation culture and learning capabilities can create a virtuous circle in which these intangible resources primarily enhance the level of utilization of e-trade and further enhance the performance of enterprises. In addition, these internal intangible resources provide the basis for achieving a competitive advantage in a company and further developing into a sustainable organization.

Second, managers should make efforts to actively utilize electronic trade, not only large companies but also small and medium-sized enterprises. In addition, government policymakers should also provide legal and institutional systems to actively utilize e-trade. Through this, it is expected that e-trade will serve as a bridge to overseas sales for small and medium-sized enterprises, which can be difficult in terms of establishing overseas networks.

This study has some limitations, despite the above contributions and implications. First, this study analyzed the factors determining the level of e-trade utilization. However, path analysis and moderator or mediator were not considered among each variable. Analysis needs to be made taking into account the path and the adjustment variables among the variables in the future. Second, a sample of this study was conducted on small and mediumsized enterprises. In future research, it will also be necessary to conduct analyses, including both large and small, and analyze the differences between small and medium-sized enterprises. Finally, it will also be necessary to develop new variables that affect the utilization of electronic trade 


\section{Reference}

Anderson, M., \& Larsen, T. S. (2008). Corporate social responsibility in global supply chains. Supply Chain Management: An International Journal , 14(2), 75-86.

Avlonitis, G. J., Kouremenos, A., \& Tozkas, N. (1994). Assessing the innovativeness of organizations and Its antecedents: project innovstrat. European Journal of Marketing, 28(11), 5-28.

Bergeron, F., \& Raymond, L. (1992). The advantages of electronic data interchange. DATABASE, 23(4), 19-31.

Bouncken, R. B., \& Kraus, S. (2013). Innovation in knowledge-intensive industries: the double-edged sword of coopetition. Journal of Business Research, 66(10), 2060-2070.

Carter, J. R., Moncska, R. M., Clauson, K. S., \& Zelinski, T. P. (1987). Education and training for successful EDI implementation. Journal of Purchasing and Materials Management, 23(2), 13-20.

Charalambos, I. L., Izak, B., \& Dexter, S. A. (1995). Electronic data interchange and small organizations: adoption and impact of technology. MIS Quarterly, 19(1), 465-485.

Choi, J. W. (2003). A study on the facilitation strategies of e-trade in the Korean SMEs. International Commerce and Information Review, 5(1), 63-83.

Choi, S. B., \& Choi, H. J. (2008). An empirical study on the usage and performance of electronic trade in Northeast Asian Nations, Journal of Korea Trade, 33(2), 211-242.

Choi. D. O. (2005). An empirical study on the practical usage of e-Trade and performance of Korean exporting companies. Journal of Industrial Economics and Business, 19(2), 681-699.

Chwelos, P., Benbasat, I., \& Dexter, S. A. (2001). Research report: empirical test of an EDI adoption model. Information Systems Research, 12(3), 304-321.

Cohen, W. M., \& Levinthal, D. A. (1990). Absorptive capacity: a new perspective on learning and innovation. Administrative Science Quarterly, 35(1), 128-152.

Crook, C. W., \& Kumar, L. R. (1998). Electronic data interchange: a multiindustry investigating using grounded theory. Information and Management, 34(2), 75-89.

Cyert, R., \& March, J. (1963). A behavioral theory of the firm. New Jersey, Prentice-Hall.

Damanpour, F. (1991). Organizational innovation: a meta-analysis of effects of determinants and moderators. Academy of Management Journal, 34(3), 555-590.

Dong, H., \& Choi, S. B. (2014). A study on the usage level and performance of e-trade in Chinese SMEs. Korea trade review, 39(1), 109-142.

Douglas, S. P., \& Craig, C. S. (1989). Evolution of global marketing strategy: scale, scope and synergy. Columbia Journal of World Business, 24(1), 47-59.

Eisenhardt, K. M., \& Martin, J. A. (2000). Dynamic capabilities: what are they?., Strategic Management Journal, $21(1), 1105-1121$.

Emmerlhainz, M. A. (1990). EDI: a total management guide. Nostrand Reinhold: Agawam,Van Publisher.

Freeman, R. E. (1994). The politics of stakeholder theory: some future directions. Business Ethics Quarterly, 4(4), 409-422.

Grover, V. (1993). An empirically derived model for the adoption of customer- based inter-organizational system. Decision Science, 24(3), 603-640.

Hakala, H. (2011). Strategic orientations in management literature: three approaches to understanding the interaction between market, technology, entrepreneurial and learning orientation. International Journal of Management Reviews, 13(2), 199-217.

Han, H. H., \& Choi, S. B. (2013). An empirical study on factors influencing e-trade utilization and performance in Korea's small and medium companies. Korea trade review, 38(1), 145-171.

Harmsen, H., Grunert, K. G., \& Declerck, F. (2000). Why did we make that cheese? an empirically based framework for understanding what drives innovation activity. $R \& D$ Management, 30(2), 151-166.

Hart, P. J., \& Sauders, C. S. (1997). Power and trust: critical factors in the adoption and use of EDI. Organization Science, 30(1), 23-42.

Heba, G. (2013). The influence of inward technology transfers and international entrepreneurial orientation on the export performance of Egyptian SMEs. Waterloo Town: Waterloo University Press.

Helfat, C. E. (1994). Evolutionary trajectories in petroleum firm R\&D. Management Science, 40(12), $1720-1747$.

Henderson, R. M., \& Cockburn, I. M. (1994). Mesuring competence? exploring firm effect in pharmacentical research. Strategic Management Journal, 15(1), 63-84.

Hughes, M., Hughes, P., \& Morgan, R. E. (2007). Exploitative learning and entrepreneurial orientation alignment in emerging young firms: implications for market and response performance. British Journal of Management, 18(4), 359-375. 
Hultman, M., Robson, J. M., \& Katsikeas, C. S. (2009). Export product strategy fit and performance: an empirical investigation. Journal of International Marketing, 17(4), 1-23.

Iacovou, L. C., Benbasat, I., and Albert, S. D. (1995). Electronic data interchange and small organizations: adoption and impact of technology. MIS Quarterly, 19(1), 465-485.

Jarvenpaa, S. L. \& Todd, P. A. (1997). Consumer reactions to electronic shopping on the world wide web. Journal of Electronic Commerce, 1(2), 59-88.

Jeong, H. E. \& Lee, S. C. (2015). A study on utilization and performance e-trading for Chinese exporters. Journal of Korea Research Society for Customs, 16(2), 247-266.

Kim B. K., \& Joo, H. Y. (2017). E-trade practices and performance of Korean enterprises. Electronic Trade Review, 15(3), 1-24.

Kim, H. M., \& Kim, J. C. (2007). A study on global e-trade performance evaluation framework. International Commerce and Information Review, 9(2), 231-253.

Kim, S. C. (2004). An empirical study on the effects of the internal firm resource on the usage level and performance of e-trade. Korea International Commercial Review, 19(2), 295-312.

Kogout, B., \& Zander,U. (1992). Knowledge of the firm, combinative capabilities and the replication of technology, Organizational Science, 3(3), 383-397.

Kuivalainen, O., Sundqvist, S., \& Servais, S. (2007). Firms' degree of born-globalness, international entrepreneurial orientation and export performance. Journal of World Business, 42(3), 253-267.

Kwon, M. S. (2009). An empirical study on utilization and performance factors of electronic trade: export companies in Korea focused. Incheon, Korea: Thesis for doctorate in University of Incheon.

Kwon W. S., \& Oh J. S. (2007). An analysis of the factors of electronic trade export performance in small and medium sized enterprises. Journal of the Institute of International Commerce and Information, 9(3), 131-149.

Lee, J. G. \& Kim, T. I. (2012). An empirical study on the determinants of usage and performance of e-trade in Chinese SMEs. The e-Business Studies, 13(4), 245-271.

Lee, J. H. (2004). An empirical study on determinants and utilizable intention of electronic trade trustworthiness. The e-Business Studies, 5(2), 31-32.

Lee, J. H. (2012) A study on the outcome of international trade practice in commitment of electronic trade, International Commerce and Information Review, 14(4), 545-562.

Lee, J. S., Kang, O. S., \& Cho, P. (2011). An empirical study on the factors affecting the usage and performance of e-trade in Chinese SMEs. International Commerce and Information Review, 13(3), 31-53.

Lee, W. C. (2006). A study on the stakeholder perspective of onlice trust. Journal of Korean Regional Development, 6(1), 173-186.

Lisboa, A., Skarmeas, D., \& Saridakis, C. (2016). Entrepreneurial orientation pathways to performance: a fuzzy-set analysis. Journal of Business Research, 69(4), 1319-1324.

Machuca, A. D., \& Barajas, R. P. (2004). The impact of electronic data interchange on reducing bullwhip effect and supply chain inventory costs. Transportation Research Part E: Logistics and Transportation Review, 40(3), 209228.

McGowon, M. K. (1994). The extent of electronic data interchange implementation: an innovation diffusion theory perspective. Kent, UK: Thesis for Doctorate in Kent University.

Noh, Y., \& Chung, Y. (2002). A study on factors influencing the usage level and performance of EDI. Information Systems Review, 11(3), 105-126.

Ozcelik, E., \& Taymaz, E. (2004). Does innovativeness matter for international competitiveness in developing countries?: the case of Turkish manufacturing industries. Research Policy, 33(3), 409-424.

Perlines, F. H., \& Lozano, E. M. (2017). Conditional mediation of competitive strategy and environment in international entrepreneurial orientation of family businesses. European Journal of Family Business, 6(2), 86-98.

Reid, S. D. (1982). The impact of size on export behaviour in small firms. In Czinkota, M. R. \& Tesar, G. (Ed.), Export Management: An International Context, New York: Prager Publishers.

Rosenkopf, L., \& Nekar, A. (2001). Beyond local search: boundary-spanning, exploration and impact in the optical disk industry. Strategic Management Journal, 22(4), 287-306.

Shim, S. H. (2013). An empirical study on the factors affecting the utilization levels, according to the reliability of the Electronic Trade. Asan, Korea: Thesis for Doctorate in Soonchunhyang University.

Siguaw, J. A., Simpson, P. M., \& Enz, C. A. (2006). Conceptualizing innovation orientation: a framework for study and integration of innovation research. Journal of Product Innovation Management, 23(6), 556-574.

Son, T. K. (2011). An empirival study through integrated IT acceptance model on the analysis of implementation and performance of e-Trate of Korean export and import firms. Seoul, Korea: Thesis for Doctorate in University of Seoul. 
Stuart, T. E., \& Podolny, J. M. (1996). Local search and evolution of technological capabilities, Strategic Management Journal, 17(1), 21-38.

Talke, K., Salomo, S., \& Kock, A. (2011). Top management team diversity and strategic innovation orientation: the relationship and consequences for innovativeness and performance. Journal of Product Innovation Management, 28(6), 819-832.

Yoon, S. J. (2000). A study on the antecedents of trust toward shopping mall web sites and its effects on purchase intention. Korean Management Review, 29(3), 353-376.

Yoon, S. Y. \& Kim, Y. D. (2011). An empirical study on usage levels and performances of e-Trade in Korea: focusing on global e-Trade services. International Business Journal, 22(4), 98-102.

Zahra, S. A., \& George, G. (2002). Absorptive capacity: a review, reconceptualization, and extension. Academy of Management Review, 27(2), 185-203. 